\section{Retrieval of a migrated Polyflex stent - a novel technique}

A 77-year-old woman with cholangitis underwent endoscopic retrograde cholangiopancreatography (ERCP), sphincterectomy, and placement of a stent (CLSO10-7; Cook Medical Inc., Bloomington, Indiana, USA) in the common bile duct.

Because the patient complained of food regurgitation and coughing spells at her follow-up appointment 3 months later, repeat ERCP was performed (TGF-160F; Olympus America Inc., California, USA) which revealed an esophageal stricture and acute inflammation ( $\bullet$ Fig. 1).

Multiple biopsies were taken, the findings of which were consistent with reflux disease. The patient was started on treatment with proton pump inhibitors.

Esophagogastroduodenoscopy (EGD) with dilation was then performed (GIF-H180; Olympus America). The stricture was dilated to $13 \mathrm{~mm}$ using Savary-Gilliard dilators (Cook Medical) under fluoroscopic guidance and a Polyflex stent (Boston Scientific, Natick, Massachusetts, USA), $9 \mathrm{~cm}$ long, with proximal diameter of $23 \mathrm{~mm}$ and middle/distal diameter of $18 \mathrm{~mm}$, was successfully placed traversing the esophageal stricture ( $\bullet$ Fig. 2 ).

Three weeks later EGD was repeated due to persistent symptoms. This revealed absence of the esophageal stent and significant worsening of the stricture to almost a pinpoint occlusion of the esophageal lumen with fibrosis and resolution of active inflammation.

Balloon dilation of the stricture was performed using a controlled radial expansion (CRE) wire-guided balloon dilation catheter (Boston Scientific) from $8 \mathrm{~mm}$ to $20 \mathrm{~mm}$. The endoscope was then passed through the stricture and the esophageal Polyflex stent was found to have migrated into the fundus of the stomach ( $\bullet$ Fig. 3). Initial attempts at stent retrieval using a snare and a tripod were unsuccessful. Further esophageal dilation was deferred, as the mucosa was extremely friable after dilation.
Subsequently the flared end of the stent was grasped with a snare (SD-240U-25; Olympus America), and, using a coagulation current of $25 \mathrm{~W}$, the outer diameter of the stent was reduced in size. The stent was then lined parallel to the esophageal lumen and retrieved successfully using hot biopsy forceps (FD-230U; Olympus America). A new Polyflex stent with a larger flare-end diameter $(25 \mathrm{~mm})$ was placed traversing the esophageal stricture. The patient remains asymptomatic and is tolerating a full liquid diet without any symptoms of dysphagia or regurgitation for over a year to date.

Polyflex esophageal stents are self-expandable polyester mesh stents that have been in use since 2001, primarily for management of refractory benign strictures of the esophagus. The proximal end of the stent is flared, while its body and distal portions are of equal diameter. Stent migration is reported in $4.5 \%-25 \%$ of patients [1,2]. If left unattended, a migrated stent has the potential to cause obstruction at the pylorus and at the ileocecal valve [3]. There have been case reports of Polyflex stent extraction by polypectomy snares without cautery [4] and foreign body extraction forceps [5] - techniques that were unsuccessful in our patient due to the tight nature of the esophageal stricture. This compelled us to explore other maneuvers for stent retrieval.

A novel technique was employed in our patient, whereby the flared end of the stent was reduced in size using coagulation current. The possibility of mucosal burning was avoided by holding the snare in the open lumen of the stomach away from the stomach wall. No literature to date has reported use of this simple and readily available technique to retrieve a migrated Polyflex stent. This novel technique appears to be safer than repeated dilations, decreases the risk of hemorrhage and perforation, and is a promising alternative especially in tight esophageal strictures such as seen in our patient.

Endoscopy_UCTN_Code_TTT_1AO_2AZ

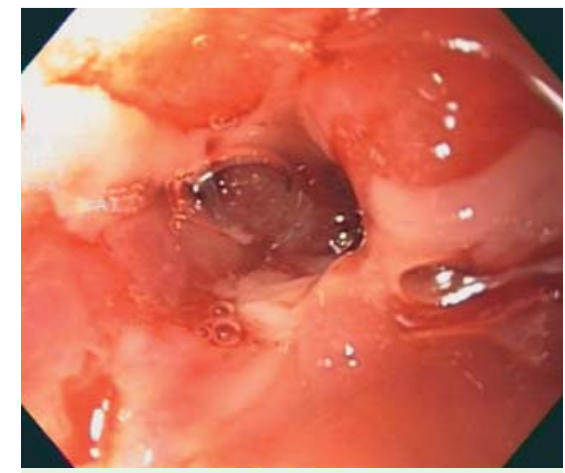

Fig. 1 Esophageal stricture proximal to esophagogastric junction with inflammation.



Fig. 2 Endoscopic image of deployed Polyflex stent.

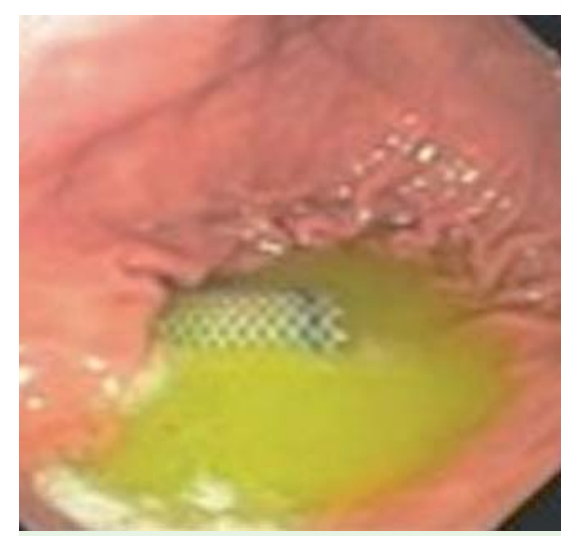

Fig. 3 Migrated stent in the stomach body.

A. M. Dinani ${ }^{1}$, R. A. Cortes ${ }^{2}$, S. Sridhara ${ }^{3}$, S. Reichert ${ }^{1}$, K. Somnay ${ }^{2}$

1 Department of Internal Medicine, New York Hospital Queens, Flushing, New York, USA

2 Division of Gastroenterology, Department of Internal Medicine, New York Hospital Queens, Flushing, New York, USA

3 Department of Internal Medicine, University of Oklahoma, Norman, Oklahoma, USA 


\section{References}

1 Conigliaro R, Battaglia G, Repici A et al. Polyflex stents for malignant oesophageal and oesophagogastric stricture: A prospective, multicentric study. Eur J Gastroenterol Hepatol 2007; 19: 195-203

2 Siersema PD. Therapeutic esophageal interventions for dysphagia and bleeding. Curr Opin Gastroenterol 2006; 22: $442-447$

3 Elphick DA, Smith BA, Bagshaw J, Riley SA. Self-expanding metal stents in the palliation of malignant dysphagia: outcome analysis in
100 consecutive patients. Dis Esophagus 2005; 18: $93-95$

4 Repici A, Conio M, De Angelis C et al. Temporary placement of an expandable polyester silicone-covered stent for treatment of refractory benign esophageal strictures. Gastrointest Endosc 2004; 60: 513 -519

5 Szegedi L, Gal I, Kosa I, Kiss GG. Palliative treatment of esophageal carcinoma with self-expanding plastic stents: A report on 69 cases. Eur J Gastroenterol Hepatol 2006; 18: $1197-1201$
Bibliography

DOI $10.1055 / \mathrm{s}-0029-1215001$

Endoscopy 2009; 41: E304-E305

(c) Georg Thieme Verlag KG Stuttgart · New York . ISSN 0013-726X

\section{Corresponding author}

A. M. Dinani, MD

Department of Internal Medicine, New York Hospital Queens

56-45 Main Street

Flushing, NY 11355

USA

amreen.dinani@gmail.com 